normally resolved in deep sea cores and ocean magnetic profiles, as the Gilsà at about $\mathbf{1 . 7}$ million years rather than, as before, the Olduvai at about 1.95 million years. Emilia and Heinrichs have also suggested (Science, 166, 1267; 1969) that on the basis of uniformity in sea floor spreading rates the long event is the Gilsà.

So what is the truth of the matter? Or rather, what is the best interpretation to be derived from currently available data? To try to settle this question Grommé and Hay have returned to look more closely at the Olduvai type section at Olduvai Gorge, Tanzania (Earth Planet. Sci. Lett., 10, 179; 1971). They show that the normal geomagnetic polarity event is represented there by five normally magnetized volcanic units -two lava flows and three ash flow tuffs. Because of the particular problems involved in the dating of these samples the time range they represent may be as little as 1.70 to 1.75 million years or as great as 1.6 to 1.9 million years. But what is certain is that a reversely magnetized tuff immediately below the normal section sets an earlier limit of 2.0 million years for the beginning of the Olduvai event. In short, on this basis the Olduvai event is no older than 2.0 million years and covers a period of no more than 0.3 million years. If the Olduvai event is limited to 1.6 to 1.8 million years, however, it is possible to assume greater linearity of both deep sea sedimentation rates and sea floor spreading rates.

Grommé and Hay thus suggest that the normally magnetized Icelandic flow dated at $1.65 \pm 0.05$ million years, which was first used to detect the Gilsà event, could well have been produced during the Olduvai. In this case, of course, the Gilsà becomes a non-event. On the other hand, there is a little evidence from a few deep sea cores that a very short event occurs just after the longer (Olduvai) one; and so it seems reasonable under the circumstances to regard this as the true Gilsà.

But are there any other normal events within the Matuyama epoch? In their 1968 paper, Cox et al. listed seven normally magnetized lavas in the range 1.95 to 2.09 million years. In the light of their previous conclusions Grommé and Hay now suggest that some or all of these flows were probably erupted before the Olduvai as they define it. Moreover, there is some evidence from ocean magnetic profiles of one, or possibly two, short normal events preceding the Olduvai. Although it seems probable that there are, in fact, two events here they cannot be distinguished unambiguously from each other by radiometric dating alone; and so Gromme and Hay propose that they be called the Reunion events because they are best represented on Reunion Island.
MARINE BIOLOGY Death in Massuchusetis

THE news of mass mortalities of marine animals tends nowadays to be ammunition for the anti-pollution lobbies. But all too easily it is forgotten that such occurrences often happen quite naturally as a consequence of extremes of temperature, low salinity and the like. They often pass unrecorded, but one instance of a natural mass mortality involving a type of fish known as the crevalle jack (Caranx hippos) caught the attention in 1969 of J. G. Hoff of Southeastern Massachusetts University.

In a brief note in Chesapeake Science $(12,49 ; 1971)$ he reports seeing on October 18, 1969, more than two hundred dead crevalle jacks in the upper reaches of the Slocum River in Massachusetts. He collected at random some fifty-five dead fish, with an average length of 3.8 inches, but he regards his estimate of the number of dead as being on the low side because he spotted about twenty herring gulls feeding on the dead fish.

Juvenile crevalle jacks are annual visitors to the Slocum River-they usually appear in the river in mid-June and leave by mid-October for southern seas. In more than two years of surveys in the Slocum River, Hoff had recorded neither pollution nor mass mortalities of fish. But where he found the dead crevalle jacks in 1969, the temperature measured only 7.4-9.0 $\mathrm{C}$; farther downstream where the temperature ranged from $9.8-10.9^{\circ} \mathrm{C}$, the fish were living quite normally. Salinity was low in the cold area, but this was not unusual and crevalle jacks had survived it in the past.

The crevalle jack seems to have been the only species of fish affected by the low temperature in the area, for several other species were caught alive with a haul seine. Hoff concludes that the cold microclimate in the Slocum River in October 1969, caused by the influx of cold spring water from a tributary combined with a sudden drop in air temperatures, killed the crevalle jacks and he says that it is likely that other late crevalle jack migrants meet the same fate in cold northern waters in the open sea.

\title{
Infrared Background points fo Low Density Universe
}

WITH the discovery of a strong background of infrared radiation, it seems that most arguments against a universal origin for cosmic rays can be countered, provided that the density of gas and dust between the galaxies is very low. In Nature Physical Science (Monday, May 17) G. Setti and L. Woltjer develop the argument first put forward a few years ago by Setti and M. J. Rees, that the energy density of the universal background of $\mathrm{X}$-radiation is linked to that of the extragalactic cosmic rays through the inverse Compton effect. When this idea was first suggested (Nature, 219, $127 ; 1968)$, it seemed that the sources of energy available to drive this process -strong extragalactic radio sourceswere not sufficient to account for the observed flux of cosmic rays. But now the discovery of powerful infrared sources has provided an additional energy source, which may tip the balance in favour of the inverse Compton process. This mechanism, by which energetic electromagnetic radiation interacts with charged particles to produce fast particles and weak radiation, is thought to operate in many astronomical objects.

The mechanism driving the infrared sources is not known, but it is sufficient for the simple model of Setti and Woltjer that the energy is being produced, and that there must certainly be electrons, protons, and magnetic fields somewhere around the sources, so that the acceleration of particles can occur. Perhaps the most interesting aspect of this latest work is the conclusion which is drawn concerning the density of matter between the galaxies. Certainly a universal cosmic ray flux will be affected by its passage through this matter, losing its energy by the production of energetic photons. The most generous estimates suggest that only a few times $10^{-7}$ particles per cubic centimetre would be sufficient to absorb almost all the cosmic rays; even the heating of such a tenuous gas to $10^{9} \mathrm{~K}$ by the cosmic ray particles would not produce detectable re-emission of the energy. The resulting ionization of the gas would, however, explain why no Lyman alpha absorption is seen in the spectra of quasars.

So although the arguments are still finely balanced, it does seem that the energy requirements for a universal origin of cosmic rays can be met. The one factor which seems implausible on some theoretical grounds-the required low density of intergalactic matterneatly explains two observational problems: the lack of Lyman alpha in quasar spectra and the lack of any other direct detection of matter between the galaxies. But most intriguing of all, if there is so little matter between the galaxies the mechanism by which galaxies form must therefore be very efficient. It is hard to see how so little matter could be left over from any conventional collapsing gas cloud model for the origin of galaxies, and this is bound to raise once again the question of galaxy formation from the inside outwards (by the expansion of a "white hole"). 